\title{
Optimization of the foam generation regime in a cylindrical channel
}

\author{
Vladimir Moskvitin ${ }^{1, *}$, Dmitry Moskvitin ${ }^{1}$, and Natalia Emelyanova ${ }^{1}$ \\ ${ }^{1}$ Irkutsk National Research Technical University, 664074, Lermontov St., 83, Irkutsk, Russia
}

\begin{abstract}
Mass and multi-purpose use of air-mechanical foams from gasliquid mixtures predetermines the need to establish the physical and technical patterns of their formation in high-efficiency generating plants. The paper presents the results of optimizing the foaming regimes, taking into account the joint influence of all probable factors coming from the technology of the process of obtaining stable disperse structures. A regression model has been developed that makes it possible to determine optimal parameters of the foaming regime with the required structure and thermal properties.
\end{abstract}

\section{Introduction}

Optimization of the process of generation of air-mechanical foams from gas-liquid mixtures with the aim of obtaining structured systems with specified technical properties should be based on the study of complex metastable physicomechanical regularities of their formation in foam generator installations.

Their defining feature is the presence of a pressure gradient and a multiplicity of foam along the length of the foaming channel, which leads to an inhomogeneous viscosity of the mixture and the instability of the velocity of its movement $[1,2]$. The a priori uncertainty of the mentioned parameters makes it very difficult to calculate the head and length of foamwater, which allow to form stable structures of the required quality.

Existing studies in this direction [3-5], as a rule, concern the evaluation of the influence of individual factors on the kinetics of the process or the change in the viscosity of the forming mixtures. At the same time, the interdependence and interdependence of all process parameters, including taking into account the inverse influence of the forming structures, is not considered. In particular, the overwhelming number of studies pertains to the analysis of the already formed foams in the cylindrical channel, which eliminates the possibility of taking into account the influence of the ratio of the initial phases, the initial level of the gas kinetics and other parameters.

The purpose of this work is to evaluate the complex effect of several factors (the foam multiplicity, its dispersion, air utilization factor, surfactant concentration) on the main parameters of the technological procedure for the formation of a priori preset quality. Taking into account operational requirements, the foam multiplicity should be within $19 \pm 1$, bubble

* Corresponding author: foamplast@list.ru 
diameter $\bar{d} \leq 500 \mu \mathrm{m}$, and the air utilization factor is up to $100 \%$, the surfactant (SF) consumption is minimal.

\section{Materials and Methods}

The investigations were carried out in an experimental setup (Fig. 1), which made it possible to obtain a continuous foam for 40-60 minutes, while controlling the flow of liquid, gas, pressure along the length of the foaming channel after 5 meters, the dispersion and the multiplicity of the foam.

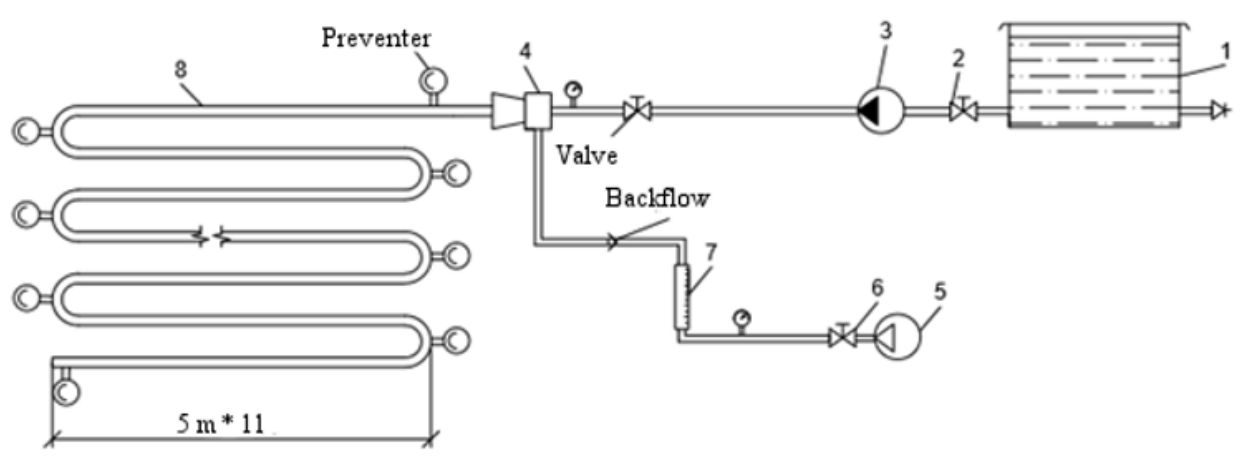

Fig. 1. The pneumohydraulic scheme of an experimental foam generator set.

A solution of a surfactant with a certain concentration was prepared in a tank (1) and pumped through a metering valve (2) with a pump (3) into a jet mixer (4), at the same time compressed air was supplied from the compressor (5) in an amount controlled by the valve (6) and flow meter (7). The gas-liquid mixture obtained in the mixer was supplied to the cylindrical channel (8), which consisted of glass tubes $25 \mathrm{~mm}$ in diameter, joined on the one side by glass adapters, and on the other hand by segments of a re-zirconium sleeve of the same diameter. Manometers were installed at the junction of the tubes with the sleeve. The total length of the foaming channel was $55 \mathrm{~m}$.

The multiplicity of the foam was determined with the aid of graduated cylinders with a volume of $0.001 \mathrm{~m}^{3}$. The number of samples depended on the density of the measurement results, but not less than $10[6,7]$ to ensure statistical representation of the data.

The dispersion of the foam and the dimensions of its basic elements are determined by the micro-photographic method using the microfiber attachment МФH-5 through the stereomicroscope МБС-2, which allows to rapidly change the magnification ratio to $15 \div 20$. The dimensions of the main elements of the foam were determined with the aid of a photographic plate with the image of a scale mesh filled with the same degree of magnification as the photographs of the foam samples. The results of each experiment calculated the air utilization factor $f$, using the expression:

$$
f=\frac{v_{\varkappa} \beta-v_{\varkappa}}{v_{2}},
$$

where $v_{\varkappa}$ - volume of solution, which went to foam formation, $\mathrm{m}^{3} ; \beta$ - foam multiplicity; $v_{2}$ - volume of air supplied to the channel, $\mathrm{m}^{3}$. 
To describe the dependences of the multiplicity $(\beta)$, the dispersion $(\bar{d})$, the coefficient of using air on the surfactant concentration and the ratio of the volume of gas to liquid, a central composition plan of the second order for two factors was applied [6, p. 52].

\section{Results}

The field of optimization of the foam regime was established on the basis of a series of search experiments (Table 1) at the following boundary limits: SF concentration $0.15-0.18 \%$, upper ratio of volumetric velocities of gas and liquid 22.5 .

Table 1. Effect of SF concentration on parameters of foam regime.

\begin{tabular}{|c|c|c|c|c|c|c|c|}
\hline \multirow[b]{2}{*}{$\begin{array}{l}\text { Concentration of } \\
\text { surfactants *, \% }\end{array}$} & & \multicolumn{2}{|c|}{$\begin{array}{l}\text { Multiplicity of } \\
\text { foam }\end{array}$} & \multirow[b]{2}{*}{$\begin{array}{l}\text { Coefficient of use } \\
\text { of air, } \%\end{array}$} & \multicolumn{3}{|c|}{ Dispersion } \\
\hline & & $\begin{array}{l}\text { Estimat } \\
\quad \text { ed }\end{array}$ & Actual & & $\begin{array}{c}\bar{d} \\
\text { Max. }\end{array}$ & $\begin{array}{c}\bar{d} \\
\min \end{array}$ & $\begin{array}{c}\bar{d} \\
\text { mediu } \\
\text { m. }\end{array}$ \\
\hline 0,10 & 24,3 & 25,3 & 18,9 & 74,7 & 1200 & 500 & 680 \\
\hline 0,13 & 23,0 & 24,0 & 22,0 & 91,7 & 930 & 410 & 590 \\
\hline 0,15 & 22,0 & 23,0 & 22,8 & 99,1 & 480 & 170 & 320 \\
\hline 0,18 & 22,5 & 23,5 & 23,5 & 100,0 & 400 & 150 & 270 \\
\hline 0,20 & 23,1 & 22,0 & 22,0 & 100,0 & 380 & 130 & 250 \\
\hline 0,26 & 22,1 & 23,1 & 23,1 & 100,0 & 330 & 120 & 220 \\
\hline
\end{tabular}

* "Volgonat" or sodium alkyl sulfonate (E30).

The mathematical model of the relationship between optimization parameters and the factors affecting them is adopted in the form of a polynomial:

$$
y=b_{0}+b_{1} x_{1}+b_{2} x_{2}+b_{11} x_{1}^{2}+b_{22} x_{2}^{2}+b_{12} x_{1} x_{2}
$$

To determine the coefficients of the polynomial (2), a rotatable compositional plan of the second order was used [8]. The locations of the experimental points are shown in Figure 2, coding factors in Table 2, and the planning matrix and the results of studies of the foam generation regime in Tables 3 .

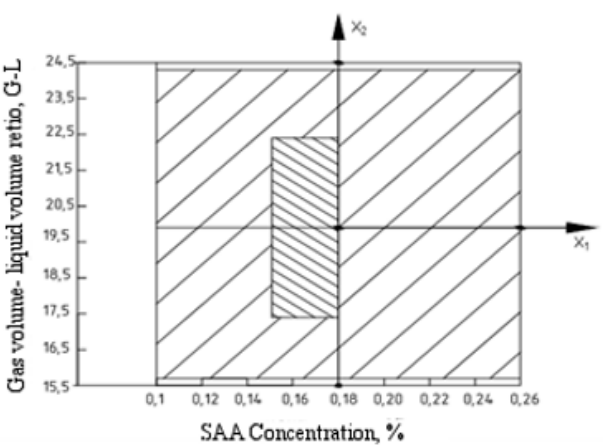

a

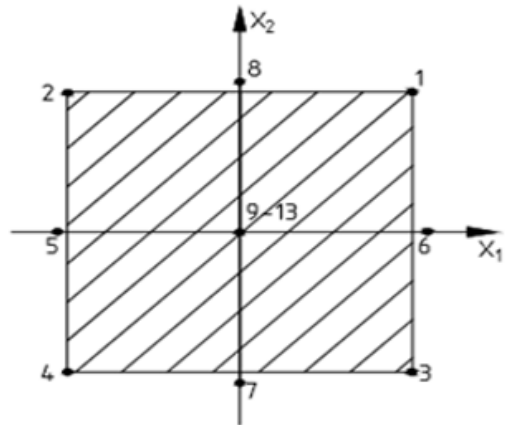

b

Fig. 2. Location of experiments of a rotatable composite plan of the second order in the system of coordinates: a) natural; b) code. 
When coding, the following designations of factors and optimization parameters were adopted: $x_{1}$ - concentration of surfactant, $\% ; x_{2}-$ the ratio of the volume velocities of the mixing phases; $\mathrm{G} / \mathrm{L}$ - foam multiplicity; $y_{2}$ - content of bubbles with a diameter of $\bar{d} \leq 500$ $\mu \mathrm{m}, \% ; y_{3}-$ the air utilization factor, $\%$.

Table 2. Coding factors.

\begin{tabular}{|c|c|c|c|c|c|c|c|}
\hline & \multirow{2}{*}{ Factor name } & \multicolumn{5}{|c|}{ Levels } & \multirow{2}{*}{$\Delta Z_{1}$} \\
\hline & & $-1,41$ & -1 & 0 & 1 & 1,41 & \\
\hline \multirow[b]{2}{*}{$\begin{array}{l}\text { For } y_{1} \\
\text { and } y_{3}\end{array}$} & $\begin{array}{l}\text { Concentration of } \\
\text { surfactants, \% }\end{array}$ & 0,1 & 0,123 & 0,18 & 0,237 & 0,26 & 0,057 \\
\hline & $\begin{array}{l}\text { The ratio of the volume of gas } \\
\text { to the volume of the liquid, } \\
\Gamma: Ж\end{array}$ & 15,7 & 17 & 20 & 23 & 24,3 & 3 \\
\hline \multirow[b]{2}{*}{ For $y_{2}$} & $\begin{array}{l}\text { Concentration of } \\
\text { surfactants, } \%\end{array}$ & 0,15 & 0,155 & 0,165 & 0,175 & 0,18 & 0,01 \\
\hline & $\begin{array}{l}\text { The ratio of the volume of gas } \\
\text { to the volume of the liquid, } \\
\Gamma: Ж\end{array}$ & 17,5 & 18,2 & 20 & 21,8 & 22,5 & 1,8 \\
\hline
\end{tabular}

Table 3. The planning matrix and the results of experimental studies of the foam generation regime.

\begin{tabular}{|c|c|c|c|c|c|}
\hline \multirow{3}{*}{$\begin{array}{l}\text { No. of } \\
\text { experience }\end{array}$} & \multirow[b]{3}{*}{$x_{1}$} & \multirow[b]{3}{*}{$x_{2}$} & \multicolumn{3}{|c|}{ Optimization options } \\
\hline & & & $y_{1}$ & $y_{2}$ & $y_{3}$ \\
\hline & & & $\begin{array}{l}\text { Multiplicity } \\
\quad \text { foam, } \beta\end{array}$ & $\begin{array}{c}\text { The content of bubbles } \\
\text { with a diameter } \bar{d} \leq 500 \\
\text { мкм, } \%\end{array}$ & $\begin{array}{c}\text { Coefficient } \\
\text { use of air } f, \%\end{array}$ \\
\hline 1 & + & + & 21,5 & 98 & 100 \\
\hline 2 & - & + & 17,5 & 100 & 87 \\
\hline 3 & + & - & 17,25 & 89 & 96,5 \\
\hline 4 & - & - & 15,5 & 50 & 74 \\
\hline 5 & $-1,41$ & 0 & 14 & 85 & 73 \\
\hline 6 & 1,41 & 0 & 20,5 & 98 & 100 \\
\hline 7 & 0 & $-1,41$ & 17 & 55 & 91 \\
\hline 8 & 0 & 1,41 & 25,5 & 99 & 100 \\
\hline 9 & 0 & 0 & 20 & 91 & 99 \\
\hline 10 & 0 & 0 & 19 & 93 & 98 \\
\hline 11 & 0 & 0 & 21 & 94 & 98,5 \\
\hline 12 & 0 & 0 & 20,5 & 95 & 100 \\
\hline 13 & 0 & 0 & 19,5 & 92 & 99,5 \\
\hline
\end{tabular}

In accordance with the chosen technique [8, p.12], the results of the experiment determined the coefficients of the regression equations (Table 4).

Comparing the numerical values of the confidence intervals (Table 5), calculated with the help of the Student's test $(t)$ and the coefficients of the regression equations (Table 4), they established their significance.

After substituting the coefficients into expression (2), the regression equations take the form:

$$
\begin{aligned}
& y_{1}=20+1,9 x_{1}+2,3 x_{2}-1,7 x_{1}^{2} \\
& y_{2}=93+6,9 x_{1}+15 x_{2}-8 x_{2}^{2}-10,3 x_{1} x_{2}
\end{aligned}
$$




$$
y_{3}=99+9,2 x_{1}-3,7 x_{2}-6,8 x_{1}^{2}-2,2 x_{2}^{2}-2,4 x_{1} x_{2}
$$

Table 4. The value of the regression coefficients.

\begin{tabular}{|c|c|c|c|}
\hline \multirow{2}{*}{ Coefficient of regression } & \multicolumn{3}{|c|}{ Optimization options } \\
\cline { 2 - 4 } & $y_{1}$ & $y_{2}$ & $y_{3}$ \\
\hline$b_{0}$ & 20 & 93 & 99 \\
\hline$b_{1}$ & 1,86 & 6,9 & 9,2 \\
\hline$b_{2}$ & 2,28 & 15,0 & 3,65 \\
\hline$b_{11}$ & $-1,7$ & 1,3 & $-6,75$ \\
\hline$b_{22}$ & 0,29 & $-8,0$ & $-2,2$ \\
\hline$b_{12}$ & 0,56 & $-10,3$ & $-2,4$ \\
\hline
\end{tabular}

Table 5. Statistical analysis of the regression equations obtained.

\begin{tabular}{|c|c|c|c|}
\hline \multirow{2}{*}{ Calculated values } & \multicolumn{3}{|c|}{ The value of the calculated values for the parameters optimize } \\
\cline { 2 - 4 } & $y_{1}$ & $y_{2}$ & $y_{3}$ \\
\hline$S_{y}^{2}$ & 0,625 & 2,5 & 0,625 \\
\hline$\Delta b_{0}$ & 0,6 & 1,49 & 0,6 \\
\hline$\Delta b_{i}$ & 0,17 & 1,19 & 0,17 \\
\hline$\Delta b_{i i}$ & 0,5 & 1,28 & 0,5 \\
\hline$\Delta b_{i j}$ & 0,67 & 1,68 & 0,67 \\
\hline$S_{a d}^{2}$ & 1,44 & 7,60 & 1,79 \\
\hline$f_{y}$ & 4 & 4 & 4 \\
\hline$f_{\text {ad }}$ & 9 & 8 & 7 \\
\hline$F_{\text {pacч. }}$ & 2,81 & 3,04 & 2,86 \\
\hline$F_{\text {maбл. }}$ & 5,9988 & 6,0410 & 6,0942 \\
\hline $\begin{array}{c}\text { Conclusion on the } \\
\text { adequacy of the } \\
\text { model }\end{array}$ & $\begin{array}{c}\text { Adequate, with a } \\
\text { significance level of } \\
0.05\end{array}$ & $\begin{array}{c}\text { Adequate, with a } \\
\text { significance level of } \\
0.05\end{array}$ & $\begin{array}{c}\text { Adequate, with a } \\
\text { significance level of } \\
0.05\end{array}$ \\
\hline \multicolumn{2}{|c|}{} & & \\
\hline
\end{tabular}

It follows from the statistical analysis of the equations obtained that the equations (3-5) are adequate to the experimental data on the multiplicity $(\beta)$, the dispersion $(\bar{d})$, the coefficient of the use of air $(f)$ from the variables $\left(x_{1}\right.$ and $\left.x_{2}\right)$, since the calculated values of the Fisher test turned out to be less than the table values at the 5\% level of significance. With their use, contour curves of equal values $\beta, \bar{d}$, and $f$ (Figure 3 ) are constructed, the analysis of which is given below. 


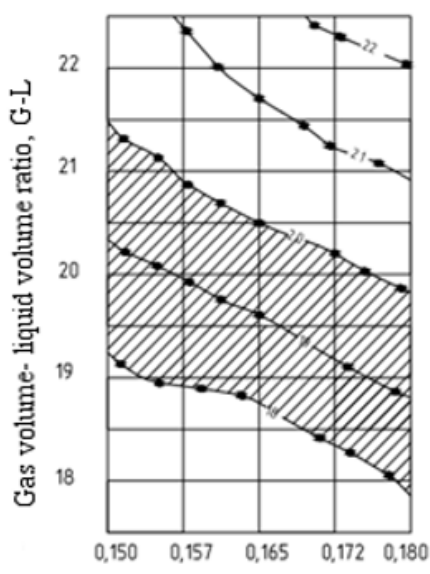

a

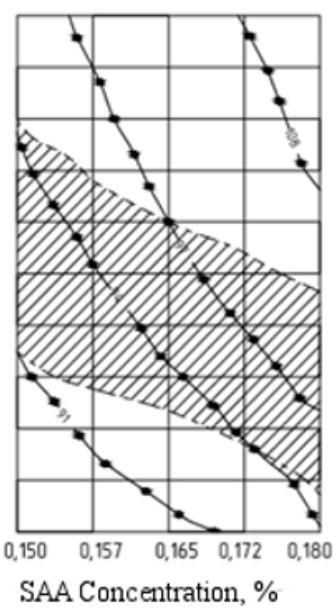

b

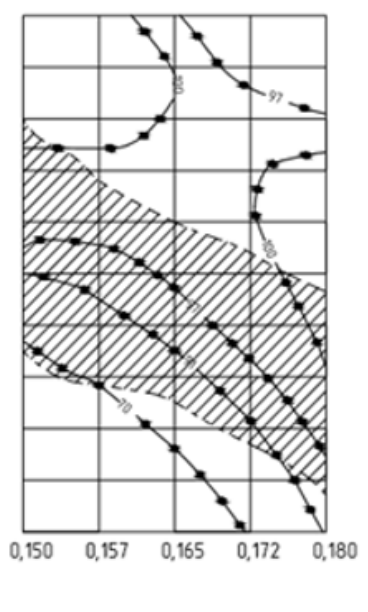

C

Fig. 3. Contour curves of equal values of parameters of the process of foam generation: $a$ ) the multiplicities $-\beta ; b)$ the air utilization factor $-f ; c$ ) contents of cells diameter $-\bar{d} \leq 500 \mu \mathrm{m}, \%$.

\section{Discussion}

It follows from Fig. 3a that foam of a given multiplicity of $19 \pm 1$ can be obtained at a surfactant concentration of $0.15 \%$, using the interval of the ratios $\mathrm{G} / \mathrm{L}$ from 19.7 to 21.4. However, in this case, the value of the coefficient $\mathrm{f}$ is relatively low, and the content of bubbles with a diameter of $\bar{d} \leq 500 \mu \mathrm{m}$ varies widely $(70 \div 100 \%)$. With a gradual increase in the surfactant concentration, air is more fully converted to foam, which leads to a decrease in the ratio of $\mathrm{G} / \mathrm{L}$ with a simultaneous increase in dissipation. Thus, at a surfactant concentration of $0.18 \%$ and a G: F ratio of $18-20, \mathrm{f}=95-97 \%$, and the content of small cells is $91-100 \%$. Further optimization is possible with a decrease in the $\mathrm{G} / \mathrm{L}$ interval. If we narrow it down to $19.5-20$, then we will obtain a foam containing $100 \%$ cells $\bar{d} \leq 500 \mu \mathrm{m}$ in diameter with $f=98 \div 99 \%$. Thus, for foams with a multiplicity of $19 \pm 1$, the optimum surfactant concentration is $0.18 \%$, and the volume ratio of the mixing phase rates is $19.5 \div 20$.

As indicated above, in all experiments we determined the pressure along the length of the foaming channel. Graphic analysis (Figure 4) of the results of measurements in the foam mode (concentration of surfactants $0.15,0.18,0.20$ and $0.26 \%$, ratio $\mathrm{G} / \mathrm{L}=19.5$ hours, 22.5), allows to determine that the function $P(L)$ is linear only at a certain section of the channel. Observations through the transparent wall, as well as microphotographic data, showed that the fracture point corresponds to the completion of the process of air dispersion and the formation of the foam structure. An increase in the concentration of surfactant leads to an acceleration of this process, which is accompanied by a reduction in the length of the section necessary to form a foam structure. This is due to the decrease in surface tension and energy costs required to form a new phase separation surface. 


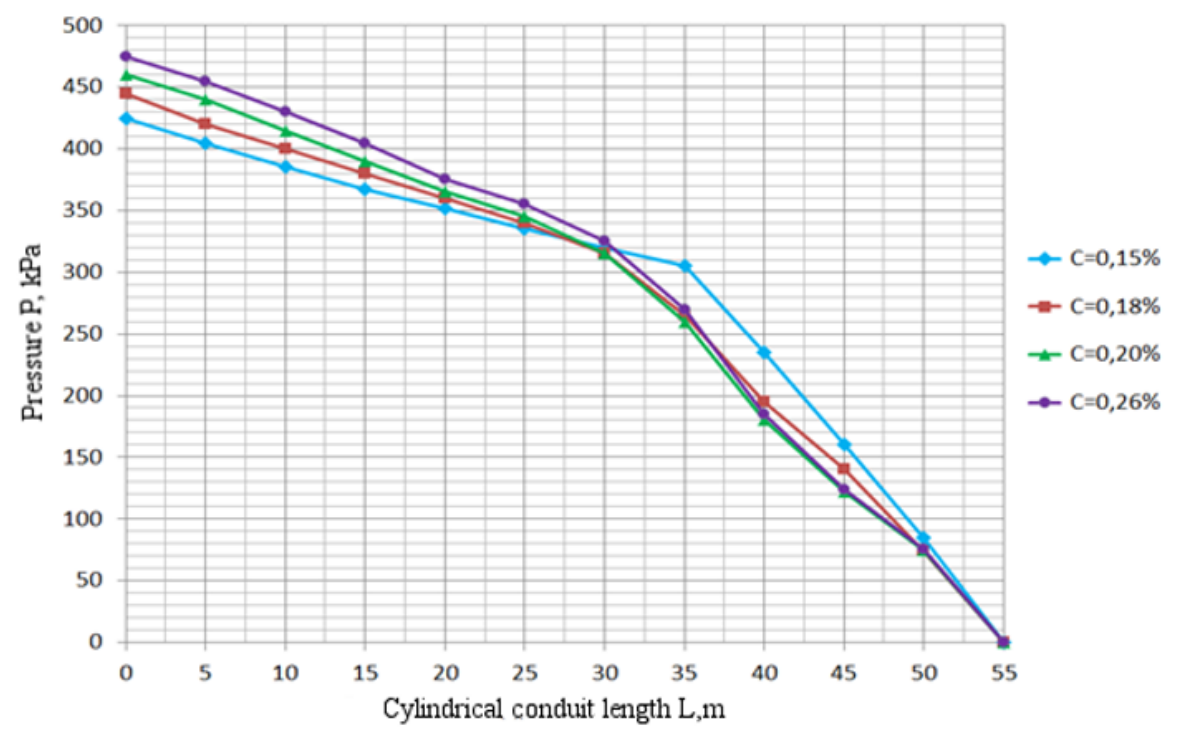

Fig. 4. Change in pressure along the length of the cylindrical channel at various concentrations $(\mathrm{C})$ of surfactants in solution: $1-\mathrm{C}=0,15 \% ; 2-\mathrm{C}=0,18 \% ; 3-\mathrm{C}=0,20 \% ; 4-\mathrm{C}=0,26 \%$

Thus, with a foam generator capacity of $23 \div 25 \mathrm{~m} 3 / \mathrm{h}$ and a diameter of the foaming channel of $25 \mathrm{~mm}$, depending on the surfactant concentration, the minimum length of the channel can vary from 24 to $35 \mathrm{~m}$, which corresponds to the ratio of the length $(L)$ to the diameter $(d) 960 \div 1400$ and the speed at the outlet of the channel is $11.0 \div 11.5 \mathrm{~m} / \mathrm{sec}$. Obviously, an increase in productivity during the transition to an industrial model will require an increase in the diameter of the foaming channel. Therefore, it seems to us important to further clarify whether the indicated relations $L: d$.

The results of studies of foam generation in a cylindrical channel were the basis for creating an industrial technology for the production of foamy heat insulators directly at the site of application of mining and construction works in the field of thermal protection of buildings [9-14], as well as creating author's certificates and patents on inventions $[15,16]$.

\section{Conclusion}

1. Regression dependencies are established that allow to determine optimal parameters of the generation regime with a priori specified characteristics of multiplicity and structure.

2. For the formation of a foam of a homogeneous structure under the optimal foam regime, the ratio of the length of the cylindrical channel to its effective diameter should be at least 1000 .

\section{References}

1. M. E. Pozin, I. P. Mukhlenov, E. Ya. Tarat, LPH, 30, 1, 45-52 (1957).

2. E. Ya. Tarat, foam and foam mode phones (Publishing House of Chemistry, Moscow, 1977).

3. A. A. Kachalov, Hydraulic resistance during the movement of air-mechanical foam through pipelines and foam jets (Moscow, 1970). 
4. K. V. Zhiltsova, V. N. Klyuev, B. B. Ptichkin, Zh. Chemistry and Chemical Technology. Proceedings of the higher educational institutions, 20, 8, 1245-1247 (1977).

5. K. V. Zhiltsova, V. N. Klyuyev, B. B. Ptichkin, G. Chemistry and Chemical Engineering. Proceedings of higher educational institutions, XVI, 10, 1610-1612 (1973).

6. A. Kriiger VFDB-Zeitschr, 2, 54-56 (1968).

7. R. John VFDB-Zeitschr, 1, 25-30 (1969).

8. T. I. Golikova, L. A. Panchenko, M. Z. Friedman, Catalog of second-order plans (Moscow University Publishing House, Moscow, 1974).

9. B. V. Levinsky, V. F. Safonov, V. G. Pyatakov, Preparation and application of foams as a heat insulator in the production of mining and construction work in harsh climatic conditions (Vneshneotorgizdat, Moscow, 1978).

10. V. G. Pyatakov, B. V. Levinsky, Yu. M. Vedyaev, V. F. Safonov, Application offoamresistant heat insulators to protect the drainage polygons from freezing (Institute "Tsvetmetinformatsiya", Moscow, 1979).

11. Guidelines for the preparation of drainage landfills using heat-insulating water-air foam (Institute "Irgiredmet", Irkutsk, 1986).

12. V. A. Moskvitin, J. Polymeric materials, 9 (88), 16-18 (2006), 10 (89), 39-43 (2006), 11 (90), 42-44 (2006).

13. Effective layered stone exterior structures with thermal insulation from the composite "Poroplast CF02." Technical conditions: TU 5741-002-16602333-2006.

14. V. A. Moskvitin, B. I. Pinus, N. A. Emel'yanova, D. V. Moskvitin, Izvestiya Vuzov. Investments. Building. The property, 4 (15), 151-157 (2015).

15. A. with. 585851 USSR. Foam generator / Auth. certificate №585851 dt. 07.09.1977.

16. Patent for invention 2283232 of the Russian Federation. Installation for the production of foamed material / Patent for invention № 2283232 dated 10.09.2006. 